DOI: $10.12957 /$ teias.2021.52722

\title{
A LITERATURA INFANTO-JUVENIL DE ERICO VERÍSSIMO NA REVISTA DO GLOBO
}

Michele Ribeiro de Carvalho

\section{Resumo}

Neste artigo, mapeiam-se e examinam-se os livros escritos por Erico Veríssimo e veiculados nas seções infantis e nas propagandas literárias da Revista do Globo desde as primeiras ocorrências possíveis de se localizar, considerando-se a peculiaridade da pesquisa histórica que privilegia a seleção, o tratamento e a análise das fontes documentais. Trata-se de uma revista de periodicidade quinzenal publicada pela casa editora de Porto Alegre, local em que o escritor também atuava como editor, tradutor e conselheiro editorial, além de autor editado. Ademais, procura-se contextualizar a Revista do Globo, problematizando sua linha editorial, os aspectos relacionados à sua produção, circulação e possível capacidade de formar a opinião pública. Tal estudo focalizou a década de 1930, especificamente os anos de 1935 a 1939, período que concentrou as produções de Veríssimo para as crianças e os jovens. Os discursos proferidos nas páginas da revista acerca dos livros e coleções publicadas pela Livraria e Editora do Globo refletem a intenção de convencer os leitores do quinzenário a adquirir as obras, o que garantiria uma boa leitura para crianças e jovens, que teriam literatura de qualidade à disposição.

Palavras-chave: literatura infanto-juvenil; erico veríssimo; revista do globo.

\section{ERICO VERÍSSIMO'S CHILD-YOUTH LITERATURE IN REVISTA DO}

$G L O B O$

\begin{abstract}
In this article, the books written by Erico Veríssimo and published in the children's sections and in the literary advertisements from the magazine Revista do Globo are mapped and examined since the first possible occurrences to be located, considering the peculiarity of the historical research which favors selection, treatment and analysis of documentary sources. The magazine is a biweekly journal from the publishing house of Porto Alegre, place where the writer also performed as an editor, translator and editorial advisor, besides being an edited author. Furthermore, it seeks to contextualize the Revista do Globo, problematizing its editorial line, the aspects related to its production, circulation and possible capacity to form public opinion. This study focused on the 1930s, specifically the years of 1935 to 1939, a period that concentrated Veríssimo's productions for children and young people. The speeches given throughout pages of the magazine concerning books and collections published by Livraria e Editora do Globo reflect the intention to convince readers of the fortnight that the acquisition of the works would guarantee a good reading for children and young people, who would have quality literature available.
\end{abstract}

Keywords: children's and youth literature; erico veríssimo; revista do globo. 


\section{LA LITERATURA INFANTIL Y JUVENIL DE ERICO VERÍSSIMO EN LA REVISTA DO GLOBO}

Resumen

En este artículo se mapean y examinan los libros escritos por Erico Veríssimo y publicados en las secciones infantiles y en los anuncios literarios de la Revista do Globo desde las primeras apariciones posibles de ubicarse, considerando la peculiaridad de la investigación histórica que favorece la selección, el tratamiento y análisis de las fuentes documentales. Es una revista quincenal de la editorial de Porto Alegre, donde el escritor también se desempeñó como editor, traductor y asesor editorial, además de autor editado. Buscase, aun, contextualizar Revista do Globo, problematizando su línea editorial, los aspectos relacionados con su producción, circulación y posible capacidad de formar opinión pública. Este estudio se centró en la década de 1930, concretamente en los años 1935 a 1939, período que concentró las producciones de Veríssimo para niños y jóvenes. Los discursos pronunciados en las páginas de la revista sobre libros y colecciones editados por Livraria e Editora do Globo reflejan la intención de convencer a los lectores de la quincena de que la adquisición de las obras garantizaría una buena lectura para niños y jóvenes, que tendrían a disposición literatura de calidad.

Palabras-clave: literatura infantil y juvenil; erico veríssimo; revista do globo.

\section{PARA INICIAR}

Escrever histórias para crianças numa linguagem que elas
compreendam e amam, éproesa que equivale a entrar numa
nursei minúscula, sem amassar os brinquedos nem acordar os
bebês que dormem. Para essa excursão perigosa épreciso ter
pés de seda.1
Erico Veríssimo (Revista do Globo, 16 de janeiro de 1937,
$\left.n^{\circ} 198\right)$

A Revista do Globo foi selecionada como objeto e fonte para este estudo, "compreendendoa como expressão de práticas e de lógicas integrantes de um sistema cultural" (VELLOSO, 2006, p. 313), na perspectiva de se entender como a literatura infanto-juvenil de Erico Veríssimo foi divulgada em suas páginas. Com esta finalidade, mapeiam-se e examinam-se os livros escritos por Veríssimo e veiculados pela Revista do Globo nas seções infantis e nos anúncios sobre literatura presentes nas páginas do periódico desde as primeiras ocorrências possíveis de se localizar, considerando-se a peculiaridade da pesquisa histórica que privilegia a seleção, o tratamento e a análise de fontes documentais como os periódicos, neste caso, a revista, e sua potencialidade para a investigação.

Acredita-se que, conforme pesquisas realizadas por Chartier, as fontes não têm sentido estável, universal e cristalizado, já que são investidas de

significações plurais e móveis, construídas da negociação entre uma proposição e uma recepção, no encontro entre formas e motivos que lhe dão sua estrutura e as competências ou expectativas dos públicos que delas se apoderam (CHARTIER, 1990, p. 103).

\footnotetext{
${ }^{1}$ Foi feita a opção de manter a grafia das citações como publicadas à época.
} 
A revista, entendida como uma "obra em movimento", é "articulada ao cotidiano e tem a capacidade de intervenção mais rápida e eficaz" (VELLOSO, 2006, p. 313). A Revista do Globo surge no ano de 1929, contexto que se destaca como particularmente expressivo, dado se tratar do momento em que se inicia o processo da moderna comunicação de massa, capaz de afetar a dinâmica do campo cultural e da história intelectual, conforme Velloso (2006).

A Revista do Globo, uma das mais importantes produções da Editora, não pôde ser localizada em acervos fora do Rio Grande do Sul, onde as várias edições estão concentradas nos arquivos do Espaço de Documentação e Memória Cultural - Delfos, da Pontifícia Universidade Católica do Rio Grande do Sul².

No presente estudo, além de mapear os livros infantis de Veríssimo, procura-se contextualizar a Revista do Globo, problematizando sua linha editorial, os aspectos relacionados à sua produção, à circulação e à possível capacidade de formar a opinião pública. Considerando a extensão do quantitativo de volumes da revista disponíveis para consulta ${ }^{3}$, foi necessário estabelecer um recorte temporal para a análise, a década de 1930, focando os anos de 1935, quando os livros para crianças e jovens escritos por Erico Veríssimo começam a ser publicados, especificamente, com $A$ vida de Joana D'Arc, a 1939, com a publicação de Aventuras no mundo da higiene. Nesse sentido, Prost (2008) elucida esse elemento constitutivo da operação historiográfica, demonstrando a necessidade de se classificar os acontecimentos e estabelecer uma periodização, que permita pensar, a um só tempo, continuidades e rupturas.

Ao longo da década de 1930, a Revista do Globo foi publicada quinzenalmente, sem interrupções. Seu acervo encontra-se completo, organizado e sob a guarda do Espaço Delfos/PUCRS, com acesso virtual. Por isso, foi possível utilizar ferramenta de busca, na qual foram inseridos: "Erico Veríssimo", "Literatura Infantil" e os títulos das obras infanto-juvenis do escritor gaúcho. Desta forma, foram localizadas propagandas, notícias e pequenas notas sobre os livros escritos por Veríssimo, destacando-se os números 165 (20 de julho de 1935), 213 (11 de setembro de 1937), 235 (27 de agosto de 1938), 237 (30 de setembro de 1938), 243 (14 de janeiro de 1939) e 253 (10 de junho de 1939) do periódico. Ademais, ressalta-se que o número 165, publicado no dia 20 de julho de 1935, trazia na capa uma representação de Joana D'Arc, em armadura reluzente, empunhando uma espada e cercada por flores, tudo sob um fundo azul; nas páginas da mesma edição podem ser lidas matérias sobre a vida de Joana D’Arc, assim como informações sobre um filme que narra sua vida.

O presente estudo está dividido em duas seções. A primeira intitulada A Revista do Globo: o "quinzenário da vida social", na qual se propõe um olhar mais apurado sobre o periódico, enfocando sua proposta editorial e aspectos materiais. Os livros infanto-juvenis de Veríssimo na Revista do Globo, segunda seção, destaca os livros de autoria de Erico Veríssimo divulgados pelo que pode ser considerado o principal periódico produzido pela Livraria e Editora do Globo.

\footnotetext{
2 A consulta ao acervo da Revista do Globo é realizada no Espaço de Documentação e Memória Cultural - Delfos, da PUCRS, localizado na cidade de Porto Alegre, em meio digital, com acesso liberado somente nas dependências do Espaço.

3 A revista era uma publicação quinzenal e circulou de 1929 a 1967.
} 


\section{A REVISTA DO GLOBO: O “QUINZENÁRIO DA VIDA SOCIAL”}

De início, fez-se necessário investigar a própria história da revista. Lançada em 1929 pela Livraria e Editora do Globo, A Revista do Globo ${ }^{4}$ tinha como proposta editorial ser um "Quinzenário de Cultura e Vida Social". Com 56 páginas em média, que retratavam a vida social de Porto Alegre e contribuições literárias de leitores, funcionava como uma espécie de vitrine dos autores e dos lançamentos e projetos da Livraria e Editora do Globo. Direcionada para homens, mulheres e crianças, com periodicidade quinzenal e tiragem de cerca de 8 mil exemplares a cada edição, de acordo com estudos divulgados no Catálogo Literário da Revista do Globo e publicados no site do espaço Delfos. Foram publicados 941 fascículos e dois números especiais: um sobre a Revolução de $1930^{5}$ e outro sobre uma grande enchente ocorrida na cidade de Porto Alegre em $1941^{6}$.

A revista surgiu em um momento de instabilidade, tanto nacional quanto internacional ${ }^{7}$, que culminou em modificações dos modos de vida, além de novos hábitos e costumes. No Brasil, novos grupos sociais precisaram ser incorporados à vida política, econômica e social. Produto desta conjuntura, a Revista do Globo legitimou-se como um veículo informativo, e, principalmente, moderno, que dava visibilidade às práticas culturais, visto estar voltada, pelo menos no início, para a literatura, mas dotada também de elementos jornalísticos.

Figura 1: Imagem da primeira página da Revista do Globo

\section{REVISTA DO

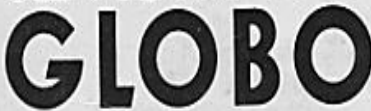 \\ A MaIOR E MELHOR REVISTA OO SUL DO BRASIL ANO XI N. 243 \\ PORTO ALEGRE, 14 DE JANEIRO DE 1030}

Fonte: Revista do Globo. Acervo Delfos/PUCRS.

\footnotetext{
${ }^{4}$ De acordo com Justino Martins, Getúlio Vargas sugeriu, em 1928, ao editor José Bertaso a fundação da Revista do Globo. [Fonte: MARTINS, Justino. Nosso Farol. In: Revista do Globo. Porto Alegre: Livraria do Globo, 21 dez. 1946. Ano 18, no 425, p. 51.]

${ }^{5}$ Movimento político-militar que derrubou a República Velha e levou ao poder Getúlio Vargas, iniciado em 3 de outubro de 1930. Neste dia, os revolucionários atacaram simultaneamente as principais unidades militares da cidade de Porto Alegre. Após se expandir pelo sul do país, Getúlio Vargas recebeu o poder das mãos de uma junta militar que havia deposto, no Rio de Janeiro, o presidente Washington Luís, de acordo com estudos realizados no CPDOC. [Fonte: CPDOC. Revolução no Rio Grande do Sul. Disponível em: https://cpdoc.fgv.br/producao/dossies/AEraVargas1/anos20/Revolucao30/RevolucaoRS. Acessado em $18 \mathrm{de}$ agosto de 2019.]

${ }^{6}$ De acordo com a publicação, essa foi a maior enchente já registrada na cidade de Porto Alegre. O nível do Lago Guaíba aumentou muito e assim ficou por vários dias, deixando o centro da cidade debaixo d'água, incluindo a Rua da Praia, onde ficava a Livraria e Editora do Globo. [Fonte: Prefeitura de Porto Alegre. Porto Alegre protegida contra enchentes como a de 1941. Consultado em 17 de maio de 2019].

${ }^{7} \mathrm{O}$ mundo enfrentava uma grande recessão econômica, cujo grande símbolo foi a quebra da Bolsa de Valores de Nova Iorque, em 1929.
} 
O exame da Figura 1 permite identificar como a revista se declarava "A maior e melhor revista do sul do Brasil". Marcada por capas em que a figura feminina tem maior destaque; a primeira edição, Figura 2, é reconhecida por uma mulher futurista sobre fundo negro, com cabelo de corte channel, abraçando um globo dourado ${ }^{8}$, fruto do trabalho de Sotero Cosme ${ }^{9}$. Muitos trabalhos sobre a Revista do Globo trazem a imagem desta capa icônica, que se tornou uma espécie de marca registrada do periódico. A grande maioria das edições da Revista do Globo estampava em suas capas mulheres com ar moderno, com cabelos mais curtos, em roupas de praia, bronzeadas ou em trajes característicos do hipismo, representações que fugiam ao ideal feminino divulgado até então.

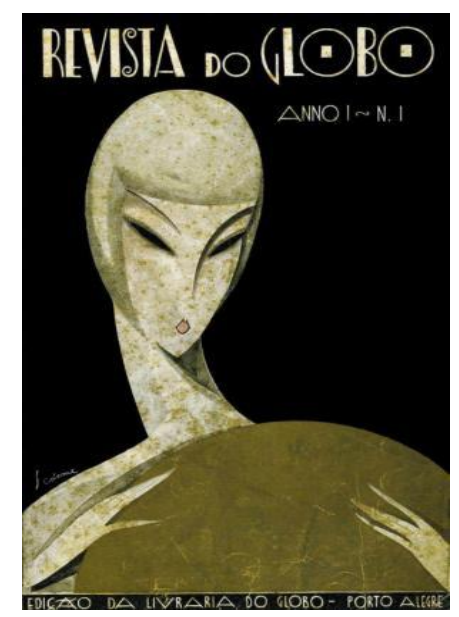

\section{Figura 2: Capa da Revista do Globo}

Fonte: Revista do Globo, 8 de janeiro de 1929, nº 1. Acervo Delfos/PUCRS.

Em sua maioria, as capas do periódico foram elaboradas por artistas do Rio Grande do Sul, que também trabalhavam as fotografias que, porventura, estampassem as capas, atribuindo cores artificialmente às imagens. Esses artistas foram estudados em diversas pesquisas sobre a revista e seu design ${ }^{10}$.

Os editoriais são considerados importantes objetos de estudo para o conhecimento da proposta ideológica do impresso. O primeiro editorial da Revista do Globo foi assinado pelo então diretor Mansueto Bernardi e trazia uma espécie de declaração de propósitos. Nele, eram reafirmados os ideais da revista:

Se propõe registrar e divulgar, com o auxílio da Livraria do Globo, tudo o que no Rio Grande houver e doravante ocorrer digno de registro e divulgação. E ainda Revista do Globo porque deseja constituir uma ponte de ligação mental e

\footnotetext{
${ }^{8}$ Essa capa alegórica, criada por Sotero Cosme, tornou-se o símbolo identificador da revista.

9 Considerado um dos melhores desenhistas do país nas décadas de 1920 e 1930 no estilo art-déco, foi também músico. Além das ilustrações na Revista do Globo, ilustrou capas de outras revistas, tais como a Revista Madrugada, em sua edição de estreia. [Fonte: LIMA, Herman. História da Caricatura no Brasil. V. 4, Rio De Janeiro, 1963.; PONTUAL, Roberto. Dicionário das artes plásticas no Brasil. Civilização Brasileira, Rio de Janeiro, 1969.]

${ }^{10} \mathrm{Um}$ importante estudo acerca da Revista do Globo e seus ilustradores, enfocando a modernidade visual do periódico e a importância da Seção de Desenho da Livraria e Editora do Globo, foi a pesquisa realizada pela Prof ${ }^{a}$. Dr ${ }^{a}$. Paula Ramos ao longo do mestrado e doutorado, publicada como o livro A MODERNIDADE IMPRESS A - Artistas ilustradores da Livraria do Globo pela Editora UFRGS com patrocínio da Petrobras. [Fonte:
} 
social entre o Rio Grande e o resto do mundo (Revista do Globo, Ano 1, $\mathrm{n}^{\circ} 1$ Preâmbulo, 1929).

Cabe ressaltar que o editorial menciona a intenção de publicar tudo o que for considerado "digno de registro e divulgação". Mas quem decide o que é digno de ser registrado e divulgado pelos impressos? Sob a direção de Erico Veríssimo por alguns anos da década de 1930, a Revista do Globo publicou um grande número de textos literários infantis, juvenis e para adultos, além de notícias sobre os eventos e a sociedade porto-alegrense e gaúcha. As seções destinadas às leitoras também estavam presentes, sugerindo tendências da moda inspirada em Paris, regras de vestimenta adequada para as senhoras, as bênçãos de ser mãe, cuidados com o cabelo. Desse modo, o que seria "digno de registro e divulgação" dizia respeito a uma classe econômica mais abastada, que frequentava bailes e usava roupas que estivessem condizentes com a moda inspirada nos modelos europeus, representantes da modernidade.

Comandando a oficina gráfica da casa editora, Veríssimo teve que escrever, de improviso, textos que ocupassem espaços vazios na Revista do Globo, conforme narra em sua autobiografia:

Com frequência os nossos paginadores me telefonavam da oficina, comunicando-me que necessitavam de matéria para encher um espaço vazio de alguns centímetros, no fim duma página. "Espere um minuto!" - dizia eu. Punha papel na máquina de escrever e improvisava um poema à maneira oriental, atribuindo-o a um poeta árabe, chinês, japonês ou persa, todos imaginários, e mandava-o para o linotipista. Não raro vinha lá de baixo um chamado aflito: "Faltam ainda cinco linhas!". Eu então ditava pelo telefone os versos suplementares em que apareciam amendoeiras floridas, cálidas areias do deserto, rosas dos jardins do Alhambra, luares sobre o Ganges... "Chega?" Havia uma pausa. "Agora tem uma linha sobrando..." - dizia o paginador. "Bom, tire fora essa flor de lótus. Faça ponto onde se lê desceu ao jardim". (VERÍSSIMO, 2005, p. 237)

Outro aspecto relacionado a padrões de comportamento feminino foram os concursos de beleza realizados nos anos 30 do século XX. As candidatas do concurso "Mais Bela do Rio Grande do Sul" foram apresentadas em reportagens e entrevistas, que podem demonstrar como certos padrões de beleza e comportamento feminino foram reforçados por meio do impresso da Livraria e Editora do Globo.

No editorial ainda se afirmava que a revista buscava a formação e a revitalização da mentalidade nacional, estando "fora" e "acima" de partidos políticos, buscando assumir uma postura "neutra". Assim, seus diretores tentavam transmitir uma sensação de pertencimento à sociedade, sem afastar possíveis leitores por filiações políticas. 


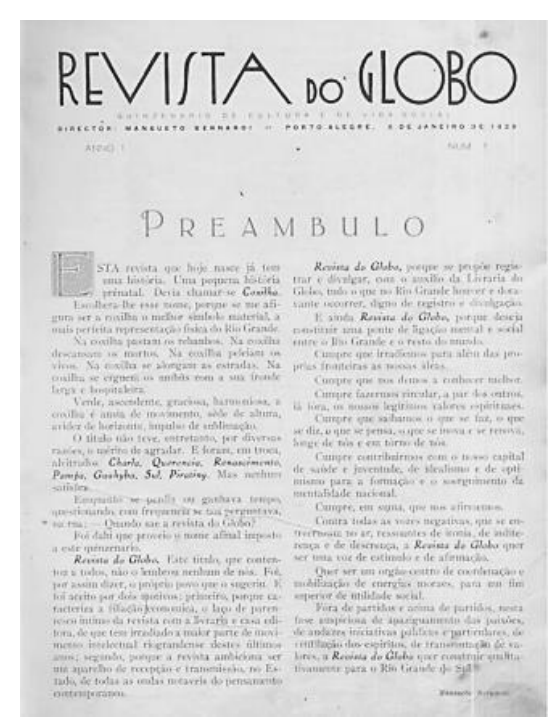

Figura 3: Preâmbulo

Fonte: Revista do Globo, 8 de janeiro de 1929, nº 1. Acervo Delfos/PUCRS.

Ainda, ao apresentar Getúlio Vargas em suas reportagens, o periódico se vale das imagens e fotografias como elemento de construção de significados e representações acerca da figura do gaúcho como instrumento político, antes mesmo da criação do Departamento de Imprensa e Propaganda, em 1939. Vargas foi retratado, de um lado, como o gaúcho que mantém suas raízes enquanto participa de um movimento de renovação política e social, demonstrando ter as qualidades necessárias para guiar a nação; por outro, com a consagração da figura política, Vargas passa a ser representado como o chefe da nação, um verdadeiro estadista. Até mesmo as imagens de Vargas veiculadas nas capas ou em matérias internas mudam do gaúcho vestido com elementos regionais para a figura austera e moderna do Presidente da República.

Entre os ilustradores que atuavam em diferentes projetos da Livraria e Editora do Globo, figuravam nomes importantes das artes plásticas do Rio Grande do Sul, como Ernest Zeuner, Sotéro Cosme, João Fahrion, Edgar Koetz e Francis Pelichek, difusores do Modernismo ${ }^{11}$ no sul do país. Naquele momento, as revistas apresentavam-se como "órgão de ponta na construção, na veiculação e na difusão do ideário moderno" (VELLOSO, 2006, p. 316). Mas, se no início, a revista utilizava apenas ilustrações ${ }^{12}$, com a modernização da imprensa na década de 1940, passou a utilizar também fotografias.

No início da pesquisa documental com a revista, foi necessário registrar informações catalográficas, como número, ano, preço de venda, e, em seguida, o sumário, assim como a equipe editorial. $\mathrm{Na}$ análise de uma fonte histórica, o pesquisador deve sensibilizar-se pela organização tanto discursiva quanto material, os documentos devem ser estudados, também, em

11 Amplo movimento cultural que repercutiu fortemente sobre a cena artística e a sociedade brasileira na primeira metade do século XX, sobretudo no campo da literatura e das artes plásticas. Considera-se a Semana de Arte Moderna, realizada em São Paulo em 1922, como o ponto de partida do Modernismo no Brasil. [Fonte: PASINI, Leandro. O Prisma dos Grupos: a difusão nacional do modernismo e a poesia de Augusto Meyer. O Eixo e a Roda: Revista de Literatura Brasileira, [S.1.], v. 25, n. 2, p. 177-199, dez. 2016. ISSN 2358-9787. Disponível em: http://www.periodicos.letras.ufmg.br/index.php/o eixo ea roda/article/view/10262. Acesso em: 25 nov. 2019.]

12 Os recursos da ilustração foram amplamente utilizados pelos periódicos, enriquecendo-os ainda mais, transformando-os em objetos atraentes, acessíveis ao público menos afeito à leitura, que recebia as mensagens por meio dos desenhos grafados de forma visualmente inteligível (MARTINS, 2001). 
si mesmos, articulando aspectos materiais e discursivos, condições de produção e utilizações estratégicas (CHARTIER, 2002).

A Revista do Globo teve como primeiro diretor Mansueto Bernardi, sendo sucedido, brevemente por João Pio de Almeida, por Octávio Tavares, Erico Veríssimo, Luiz Estrela, Justino Martins, Henrique D’Ávilla Bertaso e José Bertaso Filho. Veríssimo figura ainda como secretário da publicação, que circulou por um período longevo de 38 anos. Ao longo desse período, Veríssimo exerceu a função de secretário a partir do início do terceiro ano de publicação da revista, nela permanecendo até o final do quarto ano de publicação. Sendo assim, figura nessa função por 49 fascículos.

Nas páginas da revista, imagens e textos dividiam espaço com muitas informações, assuntos literários e artísticos, assim como acontecimentos políticos, novidades sobre a moda, o cinema e esportes. Na perspectiva de De Luca (1999), os magazines anteriores a Revista do Globo já

pretendiam revelar a moda do dia, as regras do bom gosto e bem viver, numa palavra, todo o necessário para que o seu leitor, em geral pertencente aos extratos médios da sociedade, pudesse se familiarizar com os padrões de elegância das classes abastadas (DE LUCA, 1999, p. 58).

Um conjunto de materiais educativos, como livros, periódicos e folhetins, que partilham com a instituição escolar o espaço de transmissão de valores culturais, foi disseminado após a emergência da imprensa no Brasil, ainda no século XIX. Os meios de comunicação podem ser compreendidos, portanto, como espaços informais de educação (PALLARES-BURKE, 1998), e a Revista do Globo disseminava conhecimentos sobre literatura, entre outros, para a população do Rio Grande do Sul e dos demais estados brasileiros.

O estudo da produção impressa vem ganhando espaço, na medida em que possibilita a compreensão do cenário de urbanização e modernização da sociedade brasileira. Nessa perspectiva, a Revista do Globo configura-se como espaço potencial de pluralidade de vozes de seus editores, leitores e consumidores. Observa-se, contudo, a peculiaridade da pesquisa histórica que privilegia essas fontes. Comparadas a espelhos que refletem a realidade após distorções e refrações relativas à imprensa periódica, é preciso cuidado ao intérprete que estudará esse funcionamento, de acordo com Vieira (2007).

Intitulando-se uma revista "da cidade para o mundo", a Revista do Globo alcançou leitores no Brasil e nas Repúblicas Platinas, tornando-se uma das maiores publicações nacionais e abordando os mais variados assuntos, conforme pesquisa realizada por Dalmáz (2002).

A leitura literária era assunto muito importante para o quinzenário. Ele trazia, já nas suas capas, ilustrações em que momentos de leitura eram destacados, em sua maioria, mulheres leitoras eram as retratadas. Verifique-se a Figura a seguir. 


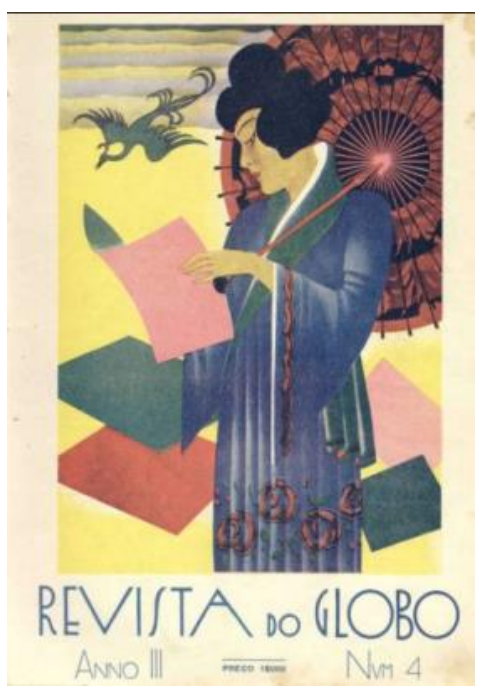

Figura 4: Capa da Revista do Globo

Fonte: Revista do Globo, 31 de janeiro de 1931, no 4. Acervo Delfos/PUCRS.

Contudo, a figura feminina não aparecia somente nas capas. Ela era veiculada nos anúncios sobre produtos de beleza, cuidados com a higiene e a saúde feminina.

Os livros sobre mulheres que tiveram seus nomes marcados na história, como Joana D'Arc, também eram veiculados no magazine. O livro de Erico Veríssimo, A vida de Joana D'Arc (1935), foi pensado para um público leitor específico, os jovens; e uma de suas propagandas afirma que esse seria "um presente ideal para o Natal".

Contudo, não somente os livros apareciam em propagandas nas páginas da Revista do Globo. A revista carioca Fon-Fon ${ }^{13}$, por exemplo, também era anunciada nas páginas do periódico.

\footnotetext{
${ }^{13}$ Revista ilustrada semanal, foi fundada por Jorge Schmidt em 1907. Procurava reforçar a ideia de uma publicação fortemente identificada com os valores da modernidade. A grande presença de fotografias, charges e caricaturas coloridas, e os recursos de ilustração, litografia e xilogravura traduziam visualmente essa identificação. Em seu editorial de lançamento, a revista apresentou-se como um semanário alegre, político, crítico e esfuziante. Pretendendo-se leve, desejava fazer rir e alegrar seus leitores com pilhérias finas e troças educadas. Até os anos de 1930 havia na revista um espaço para sátira política e crônica social, a partir de então, esse tom perdeu força, cedendo lugar à figura feminina e à divulgação de modelos de comportamento, beleza, elegância e luxo. Seções como "Culinária de bom gosto" e "Como ser bela", além de moldes para roupas, passaram a conviver com a literatura e as notícias do cotidiano. A partir da Era Vargas, portanto, houve um investimento da publicação em temáticas relacionadas à afirmação de papéis ideais para a mulher. Nota-se também a intensificação do uso de material sobre a infância, sempre de conteúdo disciplinador. [Fonte: MACENA, Fabiana Francisca. Madames, mademoiselles, melindrosas: "feminino" e modernidade na revista Fon-Fon!. 2010. 128 f. Dissertação (Mestrado em História) - Programa de PósGraduação em História, Universidade de Brasília, Brasília, 2010.]
} 


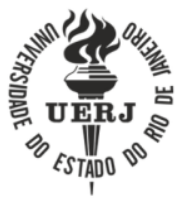

DOI: $10.12957 /$ teias.2021.52722

Figura 5: Propaganda da Revista Fon-Fon

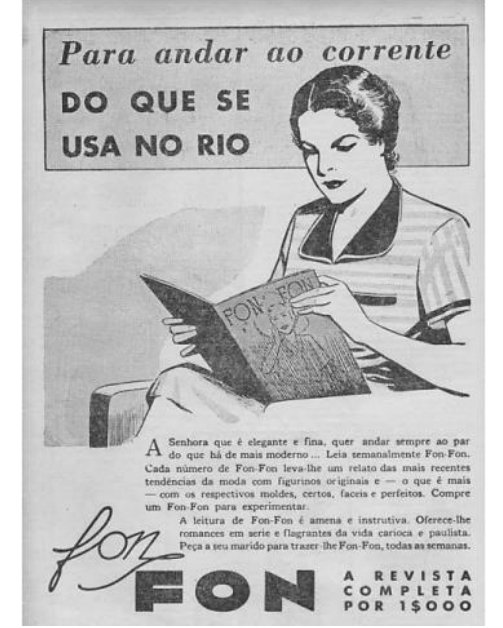

Fonte: Revista do Globo, 26 de agosto de 1939, nº 258. Acervo Delfos/PUCRS.

Sobre este anúncio é curioso notar que o mesmo ocupa toda a página da revista e apresenta a chamada "para andar ao corrente do que se usa no Rio". Voltado para o público leitor feminino, o anúncio ainda informa que a leitura da revista Fon-Fon é "amena e instrutiva", e finaliza com a frase reveladora de uma sociedade patriarcal, em que a renda familiar era responsabilidade do homem: "peça para o seu marido trazer-lhe Fon-Fon todas as semanas". À mulher casada não era permitido trabalhar sem a autorização do marido, por isso a dependência financeira. A legislação vigente à época, o Código Civil de 1916, consagrava a superioridade masculina e dava ao homem o controle da família, uma vez que ao casar, a mulher perdia sua plena capacidade, tornando-se relativamente capaz, assim como os indígenas e as crianças. Tal situação só começaria a mudar em 1962, com a edição da Lei nº 6.121, o Estatuto da Mulher Casada, devolvendo plena capacidade à mulher, que passou a ser colaboradora na administração da sociedade conjugal e não precisava mais da autorização do marido para trabalhar, o que a levou a razoável independência financeira.

Importante ressaltar também que tal revista não era direcionada a qualquer leitora, mas àquela "elegante e fina", que quisesse "andar sempre ao par do que há de mais moderno", e o que havia de mais moderno era o utilizado no Rio de Janeiro, na Belle Époque, que buscava se tornar uma sociedade bem próxima dos padrões franceses. Não por acaso, a revista estava repleta de estrangeirismos franceses em suas colunas (MACENA, 2010), tornando-se, assim, um importante instrumento no processo de criação do ideário feminino durante o período do Estado Novo (1937-1945).

Às mulheres a Era Vargas preparou, cuidadosamente, um projeto pedagógico, uma cartilha de retorno das mulheres ao lar, lugar de onde poderiam servir a pátria e a família ao mesmo tempo. Servindo a família, estariam, imediatamente, servindo a nação. Voltadas para os problemas domésticos, alienadas do contexto político, alheias aos problemas sociais e apenas com a função de mãe / esposa / educadora, não lhes era permitida qualquer afinidade ou semelhança com as funções masculinas ou da pátria. (NAHES, 2007, p. 38) 
Textos infanto-juvenis também eram publicados na revista, como Nico e o paraíso perdido e O burrico, o palhaço e outros bichos ${ }^{14}$, de autoria de Erico Veríssimo, foram publicados em 13 de agosto de 1932 e 27 de agosto de 1932, respectivamente. Os dois textos foram publicados na página de rosto do periódico, no ano de 1932, época em que Veríssimo ainda não havia iniciado a publicação de suas obras infanto-juvenis pela Livraria e Editora do Globo.

Figura 6: Cabeçalho da Página Infantil da Revista do Globo

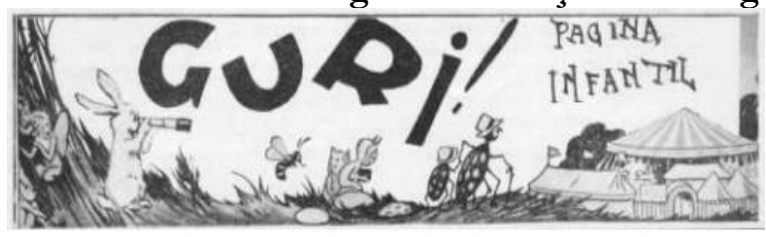

Fonte: Página Infantil (1931-1932), Revista do Globo. Acervo Delfos/PUCRS.

Para atrair o leitor infantil, a revista investia em estratégias que incluíam páginas com diagramação diferenciada e ilustrações, inclusive no cabeçalho. Tais recursos tornam clara a intenção da revista de cativar, por meio das imagens e dos textos, a atenção do leitor criança. No período de outubro de 1931 a 1936 Erico Veríssimo integrou a direção da Revista do Globo, e publicou diversos textos infantis e juvenis no periódico, evidenciando sua proposta literária, preocupada em alcançar adultos e crianças.

$\mathrm{Na}$ "Página Infantil", além das fábulas, lendas, contos, histórias em quadrinhos e poemas publicados, fotografias de bebês e crianças ganhavam destaque, sempre indicando os nomes dos pais zelosos. Outra característica observada a partir de 1933 é a inclusão de propagandas de diversos produtos nessas páginas, nem sempre relacionados ao universo infantil.

\section{OS LIVROS INFANTO-JUVENIS NA REVISTA DO GLOBO}

As crianças tinham, portanto, lugar destacado nas páginas da revista, com fotografias publicadas nas seções "Creanças Bonitas" e "Página Infantil", além das seções em que eram divulgadas as novas publicações para este público.

$\mathrm{Na}$ edição número 165 da Revista do Globo, em texto sobre o lançamento da biografia de Joana D'Arc para jovens, a editora apresenta uma defesa do estilo escolhido pelo autor Erico Veríssimo para narrar a vida da personagem.

[...] Erico Veríssimo, autor dos romances Caminhos cruzados e Música ao longe (a este último foi recentemente conferido o Grande Prêmio Machado de Assis), acaba de escrever para a Livraria do Globo uma VIDA DE JOANA D'ARC. O livro, que já se acha no prelo, a aparecer dentro de uma quinzena, é, em suma, o romance de Joana D'Arc. É a biografia sob forma de ficção. Sem fugir à verdade histórica, sem sugerir, nem sequer de leve, histórias de possíveis amores de Joana D'Arc, sem usar dos recursos tradicionalmente usados para dar caráter novelesco às biografias, Erico Veríssimo consegue contar-nos, lisamente, com colorido e leveza, a história da camponezinha predestinada. $\mathrm{O}$ que principalmente há de notar no livro é a ausência de conspicuidade na narrativa. Tudo é fluente e simples. Nada de classificações psicológicas. Nada de excursões psicanalíticas ao passado. Poucas, pouquíssimas datas. Nenhuma 14 Os títulos dos textos de Veríssimo publicados na Revista do Globo foram reproduzidos conforme a edição original
do periódico. 
descrição cansativa. As cenas do livro se sucedem rápidas, leves, dando ao leitor, no fim, a impressão de movimento, de ação contínua e trepidante. [...] A VIDA DE JOANA D'ARC nos revela realmente uma nova maneira de tratar a biografia romanceada. É livro que se lê com o interesse que costumam despertar as boas novelas de aventuras. A obra será dentro de uma quinzena apresentada ao público do Brasil num belo volume de $16 \mathrm{~cm}$ de largura por 24 de altura. Cerca de 350 páginas de impressão nítida. A capa - um desenho em muitas cores - é de Nelson Boeira Faedrich, que também fez em negro e branco as letras capitulares, o ex-libris e o pórtico em estilo gótico. [...] Joana D'Arc. In: Revista do Globo. Porto alegre, edição da Livraria do Globo, 20 jul. 1935. Ano 7, no 165, p. 6-10.)

Ao defender o estilo de Veríssimo, a editora aproveita para incluir elementos que favorecem a publicidade do livro, com a utilização de adjetivos como "belo volume", "impressão nítida", "fluente e simples", além de destacar o formato do livro, a quantidade de páginas, visualmente "coloridas e leves", e a capa com a ilustração colorida, realizada por Nelson Boeira Faedrich $^{15}$, também responsável pelas ilustrações internas da obra. Toda essa estratégia de destacar aspectos da obra que produzissem a certeza de que sua leitura seria instrutiva e prazerosa demonstra a intenção da editora de convencer os adultos que sua aquisição seria de grande importância.

Já no texto, intitulado "Pórtico para A Vida de Joana D'Arc", o próprio Veríssimo explica para a heroína de sua história porque escreveu seu livro de forma simples e descomplicada, de forma a permitir a leitura por jovens. O autor já tinha sofrido críticas, e era acusado de escrever de forma muito simples, e se autointitulava um contador de histórias ${ }^{16}$ (VERÍSSIMO, 2005).

Outro texto publicado na mesma edição da Revista do Globo, uma poesia, o autor Sérgio de Gouvêa escreve sobre o Romance da menina Joana, dedicando-o "a Erico". Acompanhada de uma imagem ilustrativa de Santa Joana D'Arc, afirma que a menina sonha com anjos e soldados que salvarão a França, que a aguarda despertar. Resume a história e anuncia que, ao lado de seus soldados, a menina salva o país e seu rei, mas é condenada à fogueira pelos ingratos que salvara da escravidão. Abraçada por Nossa Senhora, a Joana D'Arc pode voltar a sonhar, na eterna glória. E as indicações a Joana D'Arc continuam com fotos de filmes sobre a vida da jovem, imagem fac-simile da capa do livro escrito por Veríssimo, além de uma fotografia do autor das ilustrações da capa e das páginas internas do livro, Nelson Boeira Faedrich.

Em outra propaganda identificada nas páginas da Revista do Globo, nota-se a capa de 4 livros sobre mulheres, entre eles o livro escrito por Veríssimo, $A$ vida de Joana D'Arc.

\section{Figura 7: Propaganda de livros da Livraria e Editora do Globo}

\footnotetext{
15 Ilustrador, cenógrafo, cartazista, pintor e designer brasileiro, recebeu pouca atenção da crítica. Foi responsável por cartazes para a Loteria do Estado do Rio Grande do Sul, para uma cervejaria do estado, para a Loteria Federal e demandas do Departamento de Imprensa e Propaganda; além de 25 capas para a Revista do Globo. [Fonte: RAMOS, Paula. Deuses do panteão africano: os Orixás na vivência e na interpretação de Nelson Boeira Faedrich. Anais XXXVII Colóquio do Comitê Brasileiro de História da Arte, 2017]

${ }^{16}$ Importa ressaltar que a escrita de Veríssimo é de falsa simplicidade, uma vez que o escritor analisa, em seus textos, assuntos polêmicos para a época. [Fonte: CARVALHO, M. R. de. Memórias de Erico Veríssimo: primeiras leituras ao Solo de Clarineta (1912-1922). 2016. 187 f. Dissertação (Mestrado em Educação) - Faculdade de Educação, Universidade do Estado do Rio de Janeiro, Rio de Janeiro, 2016.]
} 


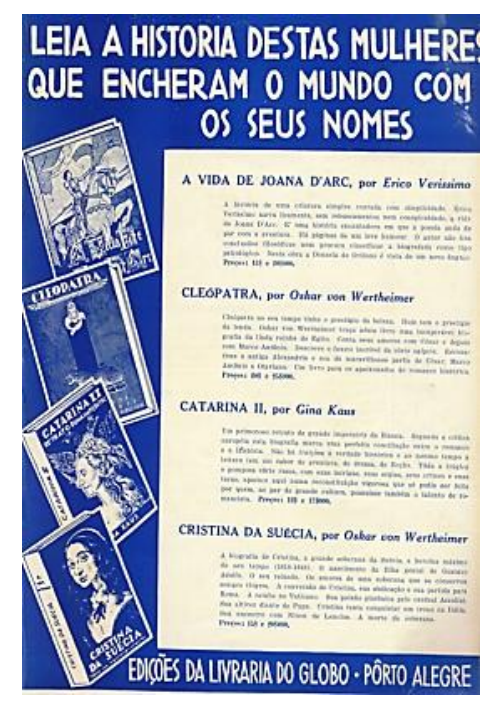

Fonte: Revista do Globo, 11 de setembro de 1937, n²13. Acervo Delfos/PUCRS.

Mais uma vez, o livro de Veríssimo sobre a vida de Joana D’Arc surge encabeçando a lista de indicações da Livraria e Editora do Globo. Seguido por um livro sobre Cleópatra ${ }^{17}$, outro sobre Catarina $\mathrm{II}^{18}$ e outro sobre Cristina da Suécia ${ }^{19}$.

Contudo, as propagandas também apareciam em seções específicas, como a intitulada "Feira Livre". Na seção do número 237 da Revista do Globo a casa editora divulga suas novas produções. Nela, lemos que os lançamentos enriquecerão a Biblioteca de Nanquinote com "mais cinco interessantes livros infantis". Mesmo nessa pequena nota divulgada pela editora, não falta um atrativo para os pais dos leitores da Biblioteca de Nanquinote; note-se que a afirmação é que a coleção será "enriquecida" com a publicação dos livros, o que parece destacar a qualidade das novas obras, que deixarão a coleção ainda mais interessante.

\footnotetext{
${ }_{17}$ Uma das mulheres mais conhecidas da história da humanidade e uma das governantes mais famosas do Egito. Sua morte por meio da picada da cobra evitaria a exposição de Cleópatra num triunfo romano. [Fonte: SILVA, Camilla Ferreira Paulino da. A construção da imagem de Otávio, Cleópatra e Marco Antônio entre moedas e poemas (44 a 27 a. C.). $189 \mathrm{f}$. Dissertação (Mestrado em História) - Faculdade de História, Universidade Federal do Espírito Santo, Espírito Santo, 2014.]

18 Imperatriz da Rússia, estabilizou o reino e conquistou prestígio entre os europeus, sendo conhecida como Catarina, A Grande. [Fonte: WIGHT, Martin. A Política do Poder. Trad. Sérgio Duarte. Brasília: Editora da Universidade de Brasília, Instituto de Pesquisa de Relações Internacionais. São Paulo: Imprensa Oficial do Estado de São Paulo, 2002].

19 Coroada rainha da Suécia em 1650, se transformou em figura lendária, que desafiou os costumes da Europa do século 17, além de importante colecionadora e patrona das artes. Declarada, ao nascer, menino, foi criada como um príncipe, recebendo treinamento em lutas e para a guerra. Pôs fim aos conflitos e estabeleceu o primeiro decreto escolar nacional, além de iniciar o primeiro jornal, em 1645, segundo estudos históricos. [Fonte: BUCKLEY, Veronica. Cristina - Rainha da Suécia. Rio de Janeiro: Objetiva. 2006].
} 
Figura 8: Seção Feira Livre

- A Coleção Nanquinote, da Livraria do Globo, será enri. quecida em breve com mais cinco interessantes livros infantis - "Outra vez os 3 porquinhos", "A Vida do Elefante Basílio" e "Urso-comMúsica-na-Barriga", de Erico Verissimo; "Histórias de Bichos", de Antônio Barata; e "Bichos da África", de Kurt Gregorius. ***

Fonte: Revista do Globo, 30 de setembro de 1938, n²37. Acervo Delfos/PUCRS.

A coleção de livros para crianças pequenas, Biblioteca de Nanquinote, reuniu, ao menos, 20 livros de autores do Rio Grande do Sul. Entre esses autores podem ser citados Erico Veríssimo e Mário Quintana. Veríssimo, além de escrever 7 livros para essa coleção, foi também seu idealizador. Seus livros foram publicados entre 1936 e 1939 em tal coleção, entretanto, outras obras suas compuseram coleções diversas da Livraria e Editora do Globo, visto sua destinação abranger diferentes faixas etárias.

$\mathrm{Na}$ mesma seção publicada no número 235 da Revista do Globo (Figura 9), é possível ler uma notícia sobre a próxima publicação da editora, o livro intitulado Viagem à Aurora do Mundo ${ }^{20}$. Dessa vez, a editora e sua direção se valem da estratégia de antecipar a notícia sobre o livro, criando expectativa sobre a obra. Além disso, deixam clara sua intenção de fazê-la circular pelas instituições escolares ao destacar seu caráter didático. Fato curioso acerca dessa obra é que em algumas propagandas era afirmado que não se tratava de uma produção para crianças.

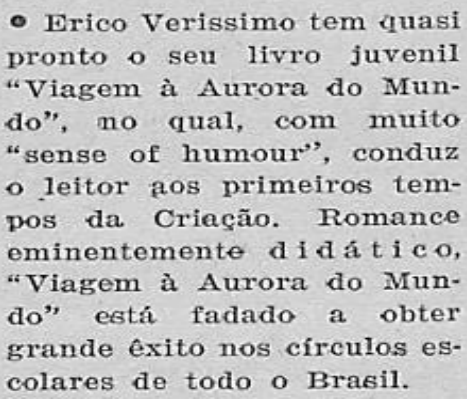

Fonte: Revista do Globo, 27 de agosto de 1938, n²35. Acervo Delfos/PUCRS.

$\mathrm{Na}$ próxima propaganda do livro localizada na Revista do Globo, mais uma vez a casa editora cria expectativa nos leitores ao divulgar que o livro estará "à venda dentro de dois meses". Dessa vez, o livro recebe a caracterização de "original aventura científica", mas não demonstra a intenção de que seja utilizado pelas escolas.

\section{Figura 10: Seção Feira Livre}

\footnotetext{
${ }^{20}$ O título do livro foi reproduzido conforme publicação original. Viagem à Aurora do Mundo conta a história do escritor Dagoberto Prata, que está de férias no lugarejo São Silvestre, quando se vê em meio a uma história de mistérios e descobertas, onde os segredos das origens do planeta, da vida e do homem lhe são revelados.
} 
VIANA MOOG E ERICO VERISSIMO

- Possivelmente, dentro de dois meses estarão à venda os dois mais recentes livros de Viana Moog e Erico Verissimo, respectivamente, UM RIO IMITA O RENO e VIAGEM A AURORA DO MUNDO. O romance de Moog está sendo aguardado com grande espectativa por se tratar de sua primeira incursão no terreno da ficção. Quanto ao livro de Erico, constitue uma original aventura científica, contada em forma de romance e onde o festejado autor de "Olhai os Lírios do Campo" nos revela coisas interessantes sôbre os animais prehistóricos.

Fonte: Revista do Globo, 10 de junho de 1939, n²53. Acervo Delfos/PUCRS.

Se na propaganda presente no número 235 da Revista do Globo o livro juvenil Viagem à Aurora do Mundo é divulgado, frisando-se que a história conta com muito "senso de humor", conduzindo o leitor por meio de um "romance didático" ao tempo da criação do mundo, e, ainda complementa-se afirmando que o livro "está fadado a obter grande êxito nos círculos escolares" de todo o país, com clara destinação às instituições escolares dos diversos estados e regiões do Brasil $^{21}$, na propaganda veiculada no número 251 da revista, o livro de Veríssimo não é divulgado de forma isolada, mas é acompanhado pelo livro de Vianna Moog, intitulado Um rio imita o Reno ${ }^{22}$, e ainda é informado que o "festejado autor de "Olhai os Lírios do Campo" é quem revela fatos sobre os animais pré-históricos. Tal distinção parece, por um lado, reafirmar a qualidade do livro juvenil, e por outro, "lembrar" aos leitores da revista sobre os demais livros escritos por Veríssimo.

Em nova edição da Revista do Globo (Figura 11), entre propagandas de outros livros publicados pela Livraria e Editora do Globo, seus editores afirmam que a Biblioteca de Nanquinote foi "enriquecida" com mais dois livros de Erico Veríssimo, ilustrados por dois dos mais famosos ilustradores da Livraria e Editora do Globo, Nelson Boeira Faedrich e Edgar Koetz.

Figura 11: Propaganda de livros da Biblioteca de Nanquinote.

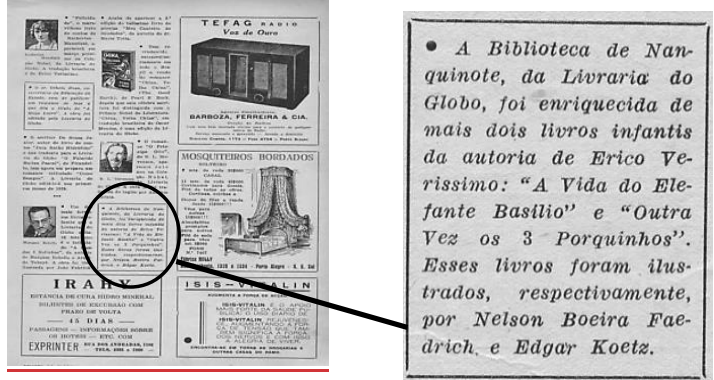

Fonte: Revista do Globo, 14 de janeiro de 1939, n²43. Acervo Delfos/PUCRS.

Tais títulos seriam publicados na Biblioteca de Nanquinote, "enriquecendo" a coleção ainda mais, segundo os editores, demonstrando a importância de ter toda a série de livros. Esse movimento de organizar os livros em coleções seria uma forma de "conquistar e atender um

${ }^{21}$ Não foi possível, contudo, devido aos limites deste estudo, identificar se o livro foi realmente adotado pelas instituições escolares do Rio Grande do Sul ou da região sul do país, uma vez que teríamos que pesquisar em documentos oficiais do período.

${ }^{22}$ De acordo com Rachel de Queiroz, o romance foi um marco na literatura brasileira, por apresentar uma cultura e uma região até então pouco conhecidas, traçando um panorama da expansão do nazismo, e descrevendo a integração dos alemães do Sul na sociedade brasileira. [Fonte: MOOG, Vianna. Um rio imita o Reno. Rio de Janeiro: Editora José Olympio, 2012.] 
público maior de leitores", de fidelizá-los, de acordo com estudo ${ }^{23}$ sobre a história do livro na França, realizado por Isabelle Olivero (1999). A Revista do Globo, dessa forma, agia como veículo formador da opinião pública, na medida em que buscava convencer seus leitores que, ao adquirir os livros publicados para seus filhos, esses teriam um bom conhecimento sobre diferentes assuntos e, dessa forma, se destacariam na sociedade. Em certa medida, os livros possuem uma carga simbólica associada, por um lado, à emancipação do homem por meio do conhecimento, por outro, ao status de uma classe superior. Por essa lógica, aquele que lê bons livros possui uma experiência cultural de grande valor, capaz de torná-lo distinto para a sociedade em que vive.

O princípio da distinção é construído a partir da familiaridade e naturalidade dos indivíduos e grupos sociais com a cultura dita legítima, de acordo com Bourdieu (2015). Logo, os motivos para uma pessoa ser distinta não estão ligados à genialidade, mas às condições de instrução recebidas por esse sujeito, e a manifestação cultural estaria condicionada pelo poder socioeconômico. Essa ideia de "distinção social" nas propagandas da Livraria e Editora do Globo buscava convencer seus leitores da importância de se possuir algo que os destacasse dos demais, que os colocasse em uma posição de notoriedade na sociedade da qual faziam parte.

\section{CONCLUSÃO}

A Revista do Globo foi pensada, neste estudo, como fonte privilegiada de divulgação da literatura infanto-juvenil e dos livros escritos por Erico Veríssimo e outros escritores do sul do Brasil. Os livros e as várias coleções organizadas pela Livraria e Editora do Globo se consolidavam no cenário regional e nacional, enquanto eram divulgados pelo periódico, considerado por seus idealizadores uma eficiente forma de propaganda não somente das obras, mas também de seus autores.

Os discursos veiculados na Revista do Globo acerca dos livros infantis e juvenis de Erico Veríssimo devem ser pensados como estratégias para alcançar maior número de leitores, não só para esses livros, como também para os romances, novelas e contos editados pela Livraria e Editora do Globo, já que as famílias tomavam conhecimento dos novos livros publicados por meio das propagandas registradas na revista.

Os livros organizados em coleções tendem a seduzir o público, criando expectativas de leitura, tornando-o fiel. Desse modo, ao divulgar o livro $A$ vida de Joana D'Arc junto a outros livros sobre figuras femininas, por exemplo, a Livraria e Editora do Globo demonstrava seu plano editorial, utilizando o nome do escritor Veríssimo para garantir a venda de outros livros por ela produzidos. Da mesma forma, ao divulgar os novos títulos da Biblioteca de Nanquinote nas páginas da Revista do Globo, os diretores do periódico procuravam, não só dar visibilidade às novas produções, como também aos livros já publicados, utilizando, inclusive, o nome de Veríssimo como garantia de leituras de qualidade para as crianças e jovens. Seu nome significava, dessa forma, bons livros e agradáveis leituras.

As diversas propagandas acerca dos livros e coleções publicadas refletem a intenção de convencer os leitores do quinzenário de que a aquisição das obras garantiria uma boa formação para crianças e jovens, além dos adultos, que teriam boa literatura à disposição. Contudo, o próprio periódico publicava leituras literárias, além das notícias e matérias sobre a vida social do estado do Rio Grande do Sul. Com textos que sinalizavam os costumes e a moda de Rio de

\footnotetext{
23 Apesar das análises de Olivero se dirigirem à França, elas são importantes para o estudo das coleções de livros publicadas no Brasil, desde que adaptadas às condições econômicas e culturais específicas do mercado editorial brasileiro.
} 
Janeiro e Paris, o magazine buscava apresentar para a sociedade porto-alegrense e gaúcha um estilo de vida considerado moderno, que colocaria a cidade e o estado mais próximos dos ideais de desenvolvimento social e cultural. As mulheres formavam um público leitor a ser alcançado, pois seriam tanto influenciadas e consumidoras dessa moda e cultura, quanto influenciariam filhos e maridos. Dessa forma, a Revista do Globo se caracterizava como um veículo formador da opinião pública e uma incentivadora de leitores literários.

\section{REFERÊNCIAS}

BOURDIEU, Pierre. A distinção: crítica social do julgamento. Porto Alegre, RS: Zouk, 2015.

BUCKLEY, Veronica. Cristina - Rainha da Suécia. Rio de Janeiro: Objetiva. 2006.

BURKE, Peter. Testemunba Ocular: Testemunha Ocular imagem e história. Bauru: EDUSC, 2004.

CARVALHO, Michele Ribeiro de. Memórias de Erico Veríssimo: primeiras leituras ao Solo de Clarineta (1912-1922). 2016. 187f. Dissertação (Mestrado em Educação) - Faculdade de Educação, Universidade do Estado do Rio de Janeiro, Rio de Janeiro, 2016.

CASTRO, Maria Helena Steffens de. O literário como sedução: a publicidade na Revista do Globo. Porto Alegre: EDIPUCRS, 2004.

CHARTIER, Roger. A História Cultural: entre práticas e representações. Lisboa: Difel, 1990.

CHARTIER, Roger. A ordem dos livros: leitores, autores e bibliotecas na Europa entre os séculos XIV e XVIII. Brasília: Editora Universidade de Brasília, 1999.

História e leitura. In: À beira da falésia: a história entre incertezas e inquietude. Porto Alegre: Editora da Universidade Federal do Rio Grande do Sul, 2002.

CPDOC. Revolução no Rio Grande do Sul. Disponível em: https://cpdoc.fgv.br/producao/dossies/AEraVargas1/anos20/Revolucao30/RevolucaoRS.

Acessado em 18 de agosto de 2019.

DALMÁZ, Mateus. A imagem do Terceiro Reich na Revista do Globo (1933-1945). Porto Alegre: EDIPUCRS, 2002.

DARNTON, Robert. O que é a história dos livros? In: DARNTON, Robert. O beijo de Lamourette: mídia, cultura e revolução. São Paulo: Companhia das Letras, 2010, p.121-201.

DE LUCA, Tânia. A Revista do Brasil: um diagnóstico para a (N)ação. SP: Fundação Editora da UNESP, 1999, 17-34.

LIMA, Herman. História da Caricatura no Brasil. V. 4, Rio De Janeiro, 1963.

MACENA, Fabiana Francisca. Madames, mademoiselles, melindrosas: "feminino" e modernidade na revista Fon-Fon!. 2010. 128f. Dissertação (Mestrado em História) - Programa de Pós-Graduação em História, Universidade de Brasília, Brasília, 2010.

MARTINS, Ana Luiza. Revistas em Revista: imprensa e práticas culturais em tempos de República, São Paulo (1890-1922). São Paulo: Edusp, 2001.

MARTINS, Justino. Nosso Farol. In: Revista do Globo. Porto Alegre: Livraria do Globo, 21 dez. 1946. Ano 18, no 425, p. 51.

MICELI, Sérgio. Imagens Negociadas: Imagens Negociadas retratos da elite brasileira (1920-1940). São Paulo: Companhia das Letras, 1996.

MONTEIRO, Charles. Porto Alegre: urbanização e modernidade - a construção social do espaço urbano. Porto Alegre: EDIPUCRS, 1995. 


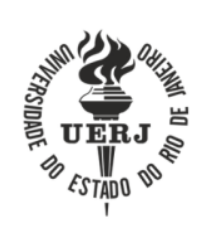

DOI: $10.12957 /$ teias.2021.52722

MOOG, Vianna. Um rio imita o Reno. Rio de Janeiro: Editora José Olympio, 2012.

NAHES, Semíramis. Revista FON-FON: a imagem da mulher no Estado Novo (1937-1945). São Paulo: Editora Arte \& Ciência, 2007.

OLIVERO, Isabelle. L'invention de la collection: de la diffusion de la littérature et des savoirs à la formation du citoyen au XIXe siècle. Paris: Institut Mémoires de l'édition contemporaine; Maison des sciences de l'Homme, 1999.

PALLARES-BURKE, Maria Lúcia Garcia. A imprensa periódica como uma empresa educativa no século XIX. Caderno de Pesquisa, Cortez, n. 104, p. 144-163, jul. 1998.

PASINI, Leandro. O Prisma dos Grupos: a difusão nacional do modernismo e a poesia de Augusto Meyer. O Eixo e a Roda: Revista de Literatura Brasileira, [S.1.], v. 25, n. 2, p. 177-199, dez. 2016. ISSN 2358-9787.

Pontifícia Universidade Católica do Rio Grande do Sul. Faculdade de Letras. Almanaque do Globo: catálogo e texto: 1917-1933 [CD-ROM]. Porto Alegre: PUCRS, 2008. 1 disco.

Pontifícia Universidade Católica do Rio Grande do Sul. Faculdade de Letras. Revista do Globo: 1929-1967 [CD-ROM]. Porto Alegre: PUCRS, 2002.1 disco.

PONTUAL, Roberto. Dicionário das artes plásticas no Brasil. Civilização Brasileira, Rio de Janeiro, 1969.

PRIORE, Mary Del (org.). História das Mulheres no Brasil. São Paulo: Contexto, 1997.

PRIORE, Mary Del (org.). História das Crianças no Brasil. São Paulo: Contexto, 1999.

RAMOS, Paula Viviane. A Modernidade Impressa: artistas ilustradores da Livraria do Globo - Porto Alegre. Porto Alegre: UFRGS EDITORA, 2016.

RAMOS, Paula. Deuses do panteão africano: os Orixás na vivência e na interpretação de Nelson Boeira Faedrich. Anais XXXVII Colóquio do Comitê Brasileiro de História da Arte, 2017.

RODRIGUES, Sandra Tessler. A literatura infantil na Revista do Globo: a que leitor se destina? [documento impresso e eletrônico]. Porto Alegre, 2007. 164 f.

SILVA, Camilla Ferreira Paulino da. A construção da imagem de Otávio, Cleópatra e Marco Antônio entre moedas e poemas (44 a 27 a. C.). 189f. Dissertação (Mestrado em História) - Faculdade de História, Universidade Federal do Espírito Santo, Espírito Santo, 2014.

TEIXEIRA, Fabiane de Souza Fraga. A interface literária da Revista do Globo / Editora do Globo. Cadernos do Centro de Pesquisas Literárias da PUCRS, Porto Alegre, v.11, n.1, p. 17-114, 2005.

THORSTENBERG, Valdiria. Página de título: uma amostra do potencial literário da Revista do Globo. 1998. 143 f. Dissertação (Mestrado em Letras) - Faculdade de Letras, Pontifícia Universidade Católica do Rio Grande do Sul, Porto Alegre, 1998.

TRUSZ, Alice Dubina. A Publicidade nas Revistas Ilustradas: o informativo cotidiano da modernidade. Porto Alegre, anos 1920. Dissertação de Mestrado. Porto Alegre: UFRGS, 2002.

VELlOSO, Mônica Pimenta. Percepção do Moderno: as revistas do Rio de Janeiro. NEVES, Lúcia Maria Bastos; MOREL, Marco; FERREIRA, Tania Maria (Orgs.). História e Imprensa. Representações culturais e práticas de poder. RJ: DP\&A, 2006, p. 312 a 331.

VERÍSSIMO, Erico. Solo de clarineta: memórias, Vol. I. 20 ed. São Paulo, Companhia das Letras, 2005 (a). 
VERÍSSIMO, Erico. Solo de clarineta: memórias, Vol. II. 20 ed. São Paulo, Companhia das Letras, 2005 (b).

VIEIRA, Carlos Eduardo. Jornal diário como fonte e como tema para a pesquisa em História da Educação: um estudo da relação entre imprensa, intelectuais e modernidade nos anos de 1920. In: OLIVEIRA, Marcus Aurélio Taborda (Org.). Cinco estudos em história e historiografia da educação. Belo Horizonte: Autêntica, 2007.

WIGHT, Martin. A Politica do Poder. Trad. Sérgio Duarte. Brasília: Editora da Universidade de Brasília, Instituto de Pesquisa de Relações Internacionais. São Paulo: Imprensa Oficial do Estado de São Paulo, 2002.

\section{Informações da autora}

Michele Ribeiro de Carvalho Universidade do Estado do Rio de Janeiro E-mail:mmichelerj@gmail.com ORCID: https://orcid.org/0000-0003-4880-8773 Link Lattes: lattes.cnpq.br/0282136354321194 